\title{
A Management Practicum Programme in Teacher Education: From Teacher to Teacher-Leader
}

\author{
Eti Gilad \\ Faculty of Education, Achva Academic College \\ POB Shikmim 79800, Israel \\ Mobile: 052-3969418Ｅ-mail: giladeti@012.net.il \\ Doi:10.5296/ijld.v4i3.5888 URL: http://dx.doi.org/10.5296/ijld.v4i3.5888
}

\begin{abstract}
This study aims to characterise the unique elements of a Management Practicum Programme in teacher education and to explore how the programme enables pre-service teachers to study the school as an educational organisation as part of their development as teacher-leaders. The study was conducted in a qualitative approach. The participants were 17 pre-service teachers learning for a B.Ed. in the Department of Education SystemsManagement at an academic college of education in Israel. A qualitative-interpretive content analysis of 34 reflective diaries, syllabus of the Department of Education System Management and a syllabus of Management Practicum Programme was performed. The results illustrate unique elements of the programme which allowed the pre-service teachers to study school as a dynamic and complex educational organisation. No longer class-teachers but teacher-leaders who perceive their role,their class and school in a systemic approach, leading towards pedagogical growth and preparing their pupils as value-oriented and educated graduates.
\end{abstract}

Key words: Teacher-Leaders, Education System Management Department Syllabus, Management Practicum Programme

\section{Introduction}

The issue of school leadership lies at the core of the public and academic debate and preoccupies researchers and educators (Avolio, 2007; Crowther et al., 2009; Inbar, 2009; Levi, 2009; Oplatka, 2010). Various theories and approaches which have developed in the field of educational leadership enhance the need for developing teachers' leadership combined with developing head teachers' leadership (Cuban, 2010; Katz et al., 1998). There is an increasing number of studies dealing with the development of teachers as effective pedagogical leaders as a structured strategy in teaching and learning processes in an era of changes and reforms (Bangs \& Frost, 2012; Frost, 2012; Muijs \& Harris, 2006). Teacher-leaders who might improve the quality of their teaching, lead the school towards pedagogical growth and prepare their pupils as value-oriented and educated human beings who are optimally integrated in society and the labour market (Harrison \& Killion, 2007; Schleicher, 2012; Sergiovanni, 2002). The research assumption is that the school leadership comprises also the teachers and that leaders play a key role in decentralising authorities and developing leaders among the school teachers (Crowrther, 2001; Crowther et al., 2002; Frank, 2013). This study explored the elements of a Management Practicum Programme and its input to pre-service teachers (hereunder "students") in the context of school leadership. 


\section{Theoretical background}

\subsection{Teacher-leaders}

There are worldwide education programmes for head teachers based on the belief that school leadership is one of the elements of school effectiveness. Some researchers argue that it has the second most important effect on pupils' learning, after the quality of teaching in class (Angelle, 2010; Frank, 2013; Leithwood et al., 2006). In addition to head teachers as leaders, researchers attribute importance to the development of teachers as educational leaders and initiators(Blasé \& Blasé, 2006; Hunzicker, 2012; Poekert, 2012). We witness more and more the growing awareness of developing teachers as leaders who shape their pupils' learning processes. The teachers are the formal and major leaders in the class and they represent the education system, its values and goals. Teachers' leadership cannot be undermined and they are the ones who affect the class climate and class management (Danielson, 2006; Goleman, Boyatzis \&McKee, 2002).

Bart (2011) argues that teachers who become leaders might experience a personal and professional satisfaction, lower level of isolation, a sense of instrumentality and new learning. Such teachers will invest at school rather than be mere residents and they will turn into professionals. Furthermore, a study of teachers' leadership which was conducted in Britain (Muijs \& Harris, 2006), indicates that teachers' leadership empowers the teachers themselves and improves the school. These researchers maintain that a variety of conditions such as a culture of trust, support, strong school leadership and innovative professional development programmes can constitute meaningful factors in the success of teacher-leaders at school. Bottery (2005) and Bryk \& Schneider (2002) stipulate that head teachers' trust in their teachers is one of the essential elements in the process of empowering teachers as teacher-leaders.

Researchers in Australia (Crowther et al., 2002) advocate acknowledgement of teachers as meaningful factors in permanent change processes at school. According to these researchers, teachers' leadership is a transformative process which can assist in leading the school and in introducing reforms. In a process of pro-active cooperation, head teachers can share the leadership with the teachers, be assisted by the teachers' creativity and together lead the school to success. Carter (2011) refers to the head teacher-teacher cooperative work as a 'parallel leadership', underscoring their mutual respect while benefitting from the teachers' advantages in the school leadership.

In the United States, the educational organisation Teacher Leadership Exploratory Consortium (2010) published a model which defines the knowledge, competences and capabilities which teacher need in order to undertake leadership functions. The standards focus on seven aspects which describe what teacher-leaders do: (1) nurture a collaborative culture in order to support the development of educators and the pupils' learning; (2) use research in order to improve the practice and the pupils' learning; (3) promote professional learning for continuing improvement; (4) facilitate improvements in teaching and pupils' learning; (5) enhance the use of assessments and data for upgrading the school and the district; (6) provide better systematic assistance services to the families and the community as well as promote the collaboration between them and the school; and (7) support pupils' learning and the teaching profession. These seven aspects highlight the goals and achievement of the report published by the researcher group, while focusing on knowledge systems, competences and elements which form the teachers' leadership.

Similarly, the researchers Harrison \&Killion (2007) argue that teacher can be teacher-leaders, proposing ten varied ways for achieving the success of the pupils and the school: (1) share teaching resources; (2) help colleagues to implement effective teaching strategies; (3) focus standards and assessments related to the curriculum; (4) teach in class with acceptance and support; (5) lead a professional community; (6) mentor new teachers; (7) share the development of the school vision and be partners to the school initiatives and activities; (8) 
assist colleagues to analyse and use the information in order to support the teaching; (9) strive to achieve constant improvement; (10) learn and develop as part of the perception of life-long learning in order to support the teaching and the learning. Data of the OECD (Schleicher, 2012) depict a comprehensive picture which is prevalent in the different countries on the topic of developing school leadership and preparation for the $21^{\text {st }}$ century. According to these data, the changes which transpire in society have far-reaching implications for teachers and teaching and learning processes as well as for school leadership. We need to re-think and re-define the teachers' role and responsibility as well as teachers' professional development as a continuing learning designed to enhance pupils' attainments.

\subsection{Syllabus of the Department of Education Systems Management at the college}

The main goal of the Department of Education Systems Management is to develop teachers' leadership in class and at school and to ensure the mobilisation and education of teachers for management positions in formal and informal education systems. A follow-up of the development processes of the education system in Israel illustrates that today teachers are required to cope with social and educational challenges which are more complex than in the past. Hence, there is a growing need to develop teachers as leaders capable of identifying their work environment and harness its powers in order to actualise the educational vision and the pedagogical performance.

During their studies at the college, the students get acquainted with a wide variety of philosophies, theories, approaches and theoretical models. Moreover, they experience and practice competences and techniques designed to help them to translate and bridge between theory and practice. The staff of the Department of Education Systems Management believes that the education system including schools should be a dynamic organisation which can trace new trends and adapt themselves to changing demands.

The key idea which orients the syllabus of the department is: developing students as autonomous people with a systemic view and developing teachers as leaders in their classroom who can identify the pupils' needs, leading them to learning and empowerment processes. The studies inculcate competences which should help the graduating students to trace and raise the human and intellectual capital of their organisation as well as the economic, political and cultural resources of their environment. Then they can channel them to constant growth, while upgrading the quality of the processes which they manage both at the class level and the organisation level (Department of Education Systems Management, 2013).

\subsection{Management Practicum Programme}

The goals of the programme are to teach in an analytical and experiential way the unique characteristics of school as an educational organisation operating in a changing technological environment; bridge between the theoretical knowledge and the applied knowledge with a focus on the managerial and organisational issues; inculcate models and tools for studying the school which functions in its social, cultural and political environment; provide tools for identifying and tracing management styles of the head teacher and position holders at school; discuss various issues emerging from the field in the context of school organisational culture; develop the students' competences of critical reflection and systemic view; and teach competences of reflection, teamwork and empowering dialogue among those attending the programme.

The major subjects learnt in the programme are: the organisation as a system in an era of change; the individual and the group; diagnosis and organisational development; change processes; competences of systemic thinking; power and authority; coping with conflicts; communication and dialogue channels; centralisation processes, decentralisation and autonomy; and reflection processes.

The programme consists of three main parts: preparing the students to theirentryto school, presenting the school profile with an emphasis on the managerial and organisational aspects of 
the head teacher and other position holders (towards the end of the $1^{\text {st }}$ semester) and submitting the applied project (at the end of the academic year). The learning processes underscore the connections to theoretical courses which the students have attended during the first academic years in the pathway. They allocate a central place to the group as a model of peer learning while sharing information. During discussions conducted at the college the students raise managerial issues following their visits at school. Moreover, there is a site which accompanies the programme where learning materials, presentations and additional relevant materials are available to the students (Gilad, 2010).

\section{The research questions}

1. What are the unique components of the Management Practicum Programme?

2. How does the Management Practicum Programme enable the students to study the school as an educational organisation as part of their development as teacher-leaders?

\section{Methodology}

\subsection{Research methodology}

This study was conducted by a qualitative approach and constitutes a case study. One of the important advantages of the case study resides in its ability to provide insights about events in the contexts and actual sites where they transpire. The case study is inductive since it presents the data from the situation regardless of the assumptions. It facilitates expression of great sensitivity, diagnosis and description of situations from different points of view (Shkedi, 2012).

\subsection{Research population}

This study was conducted for two years. The participants were $173^{\text {rd }}$-year students who studied in the Management Practicum Programme within the framework of the B.Ed. in the Department of Education Systems Management. They practiced one day per week from 0800-1400 at various schools: school in the Jewish and Arab sectors, elementary and high schools as well as state and state-religious schools. The students attending this programme participated also in practical work within the additional discipline they were studying.

\subsection{Research tools}

Data were collected from the following documents: reflective diaries written by the students, syllabus of the Department of Education Systems Management and the syllabus of the Management Practicum Programme. Every student wrote two diaries throughout the year, one diary in each semester, a total of 34 student diaries. In the reflective diaries the students documented events and situations of the school life and presented thoughts and impressions during their visit at school or thereafter. The documentation in the diaries was mainly facilitated by the students' encounter with four sources of information at school: a. talks with the head teacher and other position holders; b. observations of the school space; c. learning of documented materials found at school; and d. participation in social and pedagogical events.

\subsection{Data processing}

The data obtained from the various documents were content analysed as is customary in qualitative research. The content analysis was performed at two levels: normative content analysis in order to distinguish prominent trends and interpretive-qualitative content analysis for the purpose of disclosing essences and comprehending various insights (Shkedi, 2012).

\section{Findings}

The findings emerging from the documents analysis illustrate unique components of the programme and deep approach to learning of the school organisational culture and the head teacher's role. 


\subsection{Components of the Management Practicum Programme}

The students studied the school as an educational organisation with an emphasis on three stages: studying the school prior to their entry to it, diagnosing the school according to the model they learnt in the programme and building an applied project for the development of school.

Pre-entry to school

The pre-entry to school was the first stage in studying the school as an educational organisation. At this stage the students studied the school from different sources such as: school website, Ministry of Education website, personal or collective knowledge as well as other kinds of knowledge. As part of the practice competences of the practicum programme, the students trained at the college by means of role games and simulations as to the way they should present themselves to the head teacher and what is their request.

At school: a school-based diagnosis

At the entry to school stage the students learnt models and theories and acquired tools and competences for diagnosing the school. The first semester was mainly dedicated to the study of organisational diagnosis models, putting an emphasis on three key stages: entry to school stage, data collection stage and data analysis stage. The final product of these three stages was a written organisational diagnosis report which focused on the organisational and managerial aspects of school as an educational organisation.

Post study of school: school-based development

The second semester was devoted to the inculcation of tools for writing the applied project, through a focus and in-depth learning of the project topic. In order to choosing the topic of the project, the students were required to exercise professional judgments. For example: to what extent is the project applicable? Who are the partners to the project implementation? Will the project lead to objections on the part of the school staff and if it does, how does one deal with it? And so on.

\subsection{What was facilitated by the Management Practicum Programme?}

The programme enabled the students to get acquainted with the role of a manager who heads an educational organisation. Moreover, they studied the school as an educational organisation and the organisational structure of school. They acquired tools and competences which helped them to bridge between the theoretical and practical knowledge. They also learnt how to share various managerial dilemmas and issues with their peers and used reflection processes as part of the personal and group development.

\section{The head teacher as an educational leader}

The programme allowed students to study in-depth the head teacher's role and the competences required from a manager as head of an educational organisation from different aspects.

School vision: the practicum enabled the students to study and know the educational vision of the head teacher and the school. They learnt to identify elements from the head teacher's perception and belief and the extent to which these elements affect his or her role as head teacher. For example: to what extent does the head teacher distinguish between educational ideologies and valued-moral perceptions? How is the head teacher's credo manifested in the school credo? How compatible are the head teacher's level of statements and level of action of the head teacher?

Management style: the students identified and learnt about the head teachers' role and connected it to models of management styles and manager types which they studied in the 
programme. For example: managementaccording to the scientific management approach, inter-personal relations, loosely-coupled organisations, the $\mathrm{X}$ and $\mathrm{Y}$ theory.

Time management: the students attended management meetings, pedagogical meetings, subject coordination meetings as well as other meetings according to the matter and options they encountered. Attending these meetings as passive observers, assisted them to learn and identify styles by which meetings are conducted, time management, participants' body language, relations and coalitions in the organisation, objection and consent, etc.

Conflict settlement: the students were exposed to conflicts or crises which transpire at school at the class or organisation level. They learnt about the nature of the conflicts, their reasons and course and mainly about the way the conflict was managed by the head teacher.

Decision-making process: while observing the head teacher, the students studied his or her decision-making process. Observation of and spending time with the head teacher taught the students the following points: considerations of decision-making, obstacles in making decisions, personal style of decision-making, compliance between the personal style and the relation to the management and leadership style.

Budget management: the practicum enabled the students to be exposed to and get acquainted with the principles of the head teacher's economic perception. The head teacher applies these means when exercising economic, pedagogical and value-based judgments which are the basis of decision-making at school. Moreover, the students confronted economic dilemmas facing the head teacher as part of the education system which handles issues such as: self-management in education, choice, opening registration districts andprivatisation.

Getting acquainted with school as an educational organisation

The programme gave the students an occasion to study theoretically and practically the school organisational culture, emphasising the unique characteristics. Entry into school opened before the students a window of opportunities and facilitated exposure to social, pedagogical, political, economic, managerial and organisations aspects which are intertwined. The students realised that additional processes transpire at school beyond the learning and teaching processes. These additional processes, i.e. economic and managerial processes, affect and shape the school organisational conduct. Moreover, the students comprehended that perceiving school as a system facilitates coping with complexity and change.

School organisational structure

Being exposed to and studying the school organisational structure allowed students to obtain a super-picture of age groups, classrooms and functional specialisation. After learning the organisational structure, the students were capable of raising questions such as: what type of organisational structure exists at school? What are the meanings and implications of an organisational structure on the human activity at school? To what extent are the organisational structure and the role definitions compatible? How does the role definition helps accomplishments of the school targets? Are there relevant communication and coordination mechanisms designed to solve problems?

Bridging between the theoretical knowledge and the applied knowledge

In fact the students do not experience in practice management and coordination roles. However, the programme helped and encouraged them to connect the theoretical knowledge to the managerial practice. The programme provided practicum while inculcating relevant and updated theoretical knowledge from the field of management and of the organisation and the translation thereof into managerial tasks at school.

Peer learning 
The success of the learning in the programme was based on synergetic connections formed between the participants. These connections were essential for the programme professional conduct and the growth of each of the students and the tutor. Studies during sessions at the college offered peer leaning and built up an intimate educational community with shared goals of the experience at school principles. The fact that the students were different one from the other in their personality and professional profile, enhanced collective identification and derived maximum benefit from the group members, side-by-side with difficulties stemming from the heterogeneous composition of the group.

\section{Discussion and summary}

The programme enables the students to get acquainted from theory into practice with the school organisational culture, be exposed to the head teacher, acquire tools and competences of the school diagnosis and development, establish the qualitative connections between theory and practice as well as experience in real time the managerial dynamics of school. The learning processes at the college and the practicum at school enhanced the students' insight about the importance of leading the school as a team, while adapting the pedagogical and managerial needs to reforms and changes which penetrate the education system in a dynamic and fast way. The programme structure and components as well as reflection processes which were inherent in the programme made it possible for the students to perform an analytical and critical analysis of what they had learnt at the college and what they had experienced at school. The discourse and feedback in class constituted a part of the personal and professional development as individuals and as a group (MacLeod \& Cowieson, 2001). The awareness that reflection processes are important and essential in teaching and learning processes might assist them when they enter school as new teachers.

The success of the learning in the programme was grounded in synergetic connections formed between the participants. These connections were essential for the programme professional conduct and the growth of each of the students and the tutor (Gilad, 2001). The fact that the students were different one from the other in their personality and professional profile, enhanced collective identification and derived maximum benefit from the group members, combined with difficulties stemming from the heterogeneous composition of the group (Zilberstein, 2002).

Beyond these learning processes, the Management Practicum Programme enabled students to analyse the organisation from different points of view. According to the principles of the systemic perception, the programme helped the students to see school in an overall view and not only in the view of the class to which they were accustomed to enter and teach. The principles of the systemic perception are in line with organisational perceptions which advocate that organisational learning is a process whereby the organisation members learn about relations between actions, processes and results (Katz et al., 1998; Senge, 1997).

The students comprehended that the success of the school depends on the school leadership. Research of leadership indicates that head teachers have the competences and skills of leaders in an age of changes and complexity. They simultaneously wear more than one hat and are required to function as professionals among the staff, have personal skills of involving the staff in decision-making processes and encourage teamwork. Thus, they lead the school, teachers and pupils to long-term learning and social attainments (Fuchs, 1995; Schleicher, 2012).

This insight about the centrality of head teacher as the school leader, made the students comprehend teachers' leadership at school. The deep meaning of these insights is the need and necessity to re-define teachers' role in light of the reforms and needs of the education system. Furthermore, it is crucial that teachers embrace and internalise competences and capabilities of pedagogical leadership in the teaching and learning processes. No longer a class-teacher whose role is limited to teaching in class but an active teacher, part of the organisation who plays an 
active role in the school life, the school development and growth as an educational organisation (Harrison \& Killion, 2007; Schleicher, 2012).

\section{References}

Achva Academic College (2013). Syllabus of the Department of Education Systems Management for B.Ed. studies. Israel: Achva Academic College. [Hebrew]

Angelle, P. S. (2010). An organizational perspective of distributed leadership: A portrait of a middle school. Research in Middle Level Education, 33(5). 1-16.

Avolio, B. J. (2007). Promoting more integrative strategies to leadership theory building. American Psychologist, 62(1), 25-33.

Bangs, J.,\& Frost, D. (2012). Teacher Self-Efficiency, Voice and Leadership: Towards a Policy Framework for International Education, A report on an international survey of the views of teachers and teacher union officials. Education International Research Institute. Cambridge: Leadership for Learning University ofCambridge Faculty of Education.

Barth, R. (2001). Teacher Leader. Phi DeltaKappan, 82(6), 443-410.

Blase, J., \& Blase, J. (2006). Teachers bringing out the best in teachers: A guide to peer consultation for administrators and teachers. Thousand Oaks, CA: Corwin Press.

Bottery, M. (2005). Trust: its importance for educators. Management in Education, 18, 6-10. Bryk, A.,\& Schneider, B. (2002). Trust in Schools: A core resource for improvement, New York, Russell Sage Foundation.

Crowther, F. (2011). From School Improvement to Sustained Capacity: The ParallelLeadership Pathway, Foreword by andy Hargreaves. Thousand Oaks, CA: Corwin Press.

Crowther, F., Ferguson, M.,\& Hann, L. (2009). Developing teacher leaders: How teacher leadership enhances school success. 2nd ed.. Thousand Oaks, CA: Corwin Press.

Crowther, F., Kaagan, S., Ferguson, M., \& Hann, L. (2002). Developing Teacher Leaders. How Teacher Leadership Enhances School Success. Thousand Oaks, California: Corwin Press, Inc.

Cuban, L. (2010). The reform returns again and again. In G. Fisher, \& N. Michaeli (Eds.), Change and improvement in education systems. An anthology of articles (pp. 24-50). Jerusalem: Branco Weiss Institute and Avney Rasha Institute. [Hebrew]

Frost, D. (2012). From professional development to system change: teacher leadership and innovation, Professional Development in Education, 38 (2), 205-227.

Frank, A. (2013). Leadership motivating to practice and involvement: Nine steps on the way from management to leadership. MOFET Bulletin,51, 82-88. [Hebrew]

Fuchs, I. (1995). Change as a way of life in educational institutions. Tel Aviv: Cherikover Publications. [Hebrew].

Gilad, E. (2001). Continuing professional development of teachers at district teacher centres: In-service training courses and coaching as a whole. Maof Vemaasse, 7, 79-96, [Hebrew]

Gilad, E. (2010). Syllabus of Practicum in Management. Department of Education Systems Management, Achva Academic College. [Hebrew]

Goleman, D., Boyatzis, R., \& McKee, A. (2002). The new leaders, actualizing the power of emotional intelligence and its role in the leadership. Tel Aviv: Matar Publications. [Hebrew]

Harrison, C.,\& Joellen Killion, J. (2007). Ten Roles for Teacher Leaders.Educational Leadership, Sept 2007, 65(1), 74-77. 
Hunzicker, J. (2012). Professional development and job-embedded collaboration: how teachers learn to exercise leadership. Professional Development in Education, 38 (2), 267-289.

Inbar, D. (2009). Educational leadership in an age of contradictions. Hed Hachinuch, 4(83), 52-54. [Hebrew]

Katz, N., Altman, A., Poper, M., \& Lifschitz, R. (1998). The organisation as a learning system - An overall perception of learning and improvement processes in organisations. Organisational Development in Israel, 5. [On-line] Available: library.leadersnet.co.il [Hebrew]

Levi, A. (2009). Pedagogical leadership. Hed Hachinuch, 4(83), 70-71. [Hebrew]

Leithwood, K., Day, C., Sammons, P., Harris, A.,\& Hopkins, D.(2006).Seven strong claimsabout successful school leadershipNottingham, National College for School Leadership.

MacLeod, D. M., \& Cowieson, A. R. (2001). Discovering Credit where Credit is Due: Using autobiographical writing as a toll for voicing growth, Teacher andTeaching: Theory and Practice, 7(3).

Muijs, D., \& Harris, A. (2006). Teacher led school improvement: Teacher leadership in the UK. Teaching and teacher education, 22(8), 961-972.

Oplatka, I. (2010). Fundamentals of educational management - Leadership and managementin educational organisation. Haifa: Pardess Publishing. [Hebrew]

Poekert, P. E. (2012). Teacher leadership and professional development: examining links between two concepts central to school improvement. Professional Development inEducation, 38(2), 169-188.

Sense, P. (1997). The learning organisation. Tel Aviv: Matar Publications. [Hebrew]

Sergiovanni, T. J. (2002). Managing a school: Theoretical and practical aspects. Tel Aviv: Open University.

Schleicher, A. (Ed.) (2012). Preparing Teachers and Developing School Leaders for the 21st Century: Lessons from around the World,OECD Publishing.[Online] Available: http://dx.doi.org/10.1787/9789264xxxxxx-en

Shkedi, A. (2012). The meaning behind the words, chapters 4-5. Tel Aviv: Ramot Publishing. [Hebrew]

Teacher Leadership Exploratory Consortium (2010). Teachers as Leaders: What itTeaches. Educational Leadership, 69 (2), 8-23.

Zilberstein, M. (2002). Guidelines for programme of practicum studies in pedagogical tutoring

- Work Paper No. 1. Tel Aviv: MOFET Institute Publications. [Hebrew] 